\title{
Geniş yapraklı yabancı otların kontrolünde organik herbisitlerin kullanımı
}

\author{
Onur KOLÖREN ${ }^{1}$, W. Thomas LANINI ${ }^{2}$
}

10rdu Üniversitesi, Ziraat Fakültesi, Bitki Koruma Bölümü, ORDU

${ }^{2}$ Kaliforniya Üniversitesi, Bitki Bilimleri Bölümü, Davis, Kaliforniya, ABD

Alınış tarihi: 19 Nisan 2017, Kabul tarihi: 01 Şubat 2018

Sorumlu yazar: Onur KOLÖREN, e-posta:koloren@yahoo.com

\section{$\ddot{0} \mathbf{z}$}

Organik tarımda yabancı otlar ile mücadele önemli bir sorundur. Son yllarda bu amaçla organik herbisitler kullanılmaktadır. Bu çalışmada kontakt etkili organik herbisitlerden BioLink \% 4 ve \% 6, Matran ${ }^{\circledR} \quad$ EC $\% 10$ ve Weed Pharm \% 100 konsantrasyonları adjuvan olarak Organik BioLink \% 1, Silwet $\AA^{\circledR}$ Eco Spreader \% 1 ve Break-Thru $₫$ S 240 $\% 1$ uygulama dozları yazlık kültür bitkilerinde görülen geniş yapraklı yabancı ot türlerinden Amaranthus retroflexus L. (horoz ibiği), Abutilon theophrasti L. (imam pamuğu) ve Solanum nigrum L. (it üzümü)'un kontrolündeki etkinliği araştırılmıştır. Sonuç olarak 15. gün sayımları dikkate alındığında $A$. retroflexus ve $A$. theoprastii için BioLink \% $6+$ Organik BioLink \% 1 adjuvan uygulaması sırasıyla \% 100 ve \% 84.83 olarak etkili bulunmuştur. S. nigrum bitkisinde ise BioLink \% 6 + Organik BioLink \% 1 adjuvan, Matran ${ }^{\circledR}$ EC $\% 10+$ Organik Biolink \% 1 adjuvan ve BioLink \% 4 + Silwet* Eco Spreader \% 1 adjuvan uygulamaları \% 100 etkili bulunmuştur.

Anahtar kelimeler: Amaranthus retroflexus L., Abutilon theophrasti L., Solanum nigrum L., organik, herbisit

Using of organic herbicides to control of dicotyledone weeds

\footnotetext{
Abstract

Weed control is mainly problem in organic farming. In recent years organic herbicides have been used for this purpose. In this study, contact effective different organic herbicides (BioLink $4 \%$ - $6 \%$, Matran® EC $10 \%$ and Weed Pharm $100 \%$ ) with
}

surfactant (Organic BioLink $1 \%$, Silwet* Eco Spreader $1 \%$ and Break-Thru® S 240 1\%) were used to control of dicotyledones weed species Amaranthus retroflexus L. (redroot pigweed), Abutilon theophrasti L. (velvetleaf) and Solanum nigrum L. (black nightshade). As a results, in 15 th day for evaluation, BioLink \% 6 + Organic BioLink \% 1 was effective on $A$. retroflexus ve $A$. theoprastii $100 \%$ and $84.83 \%$, respectively. For $S$. nigrum, BioLink \% $6+$ Organic BioLink \% 1, Matran® EC \% $10+$ Organic BioLink \% 1 and BioLink \% 4 + Silwet ${ }^{\circledR}$ Eco Spreader \% 1 were effective $100 \%$.

Key words: Amaranthus retroflexus L., Abutilon theophrasti L., Solanum nigrum L., organic, herbicide

\section{Giriş}

Türkiye'nin her bölgesinde organik tarımsal faaliyet yapılmakta olup 71472 çiftçi ile 842216 ha alanda 208 çeşit üründen 1642235 ton verim alınmaktadır (Karaaslan, 2015). Günümüzde organik tarım üretim alanlarında yetiştiricilik problemlerinden bitki koruma sorunları ile mücadele en önemli ve zorunlu kısmı oluşturmaktadır. Bitki koruma sorunlarından olan yabancı otların doğrudan veya dolaylı yollarla vermiş̧ oldukları zararları, ekonomik zarar eşiği seviyesinde tutmak için birçok mücadele yöntemi geliştirilmiş̦tir. Organik tarımda kültürel, mekaniksel, fiziksel, biyolojik yabancı ot mücadelesi yanında organik herbisitlerde kullanılmaktadır. Bunlar organik içerik olarak yağ, asit ve sabun gibi doğal bileşiklerdir ve EPA tarafından minimum riskli pestisitler içerisinde sınıflandırılmaktadır (EPA, 2008). Organik ruhsatlı herbisit olmayıp birçok doğal içerikli ürün, sertifikasyon firmaları tarafından onay alanlar organik tarımda kullanılmaktadır ve 
ABD Tarım Bakanlığı (USDA) tarafından tanınmış sertifikasyon firmalarının başında Organik Materyal Denetleme Enstitüsü-ABD (OMRI) gelmektedir (Dayan ve ark., 2010). Ülkemizde sertifika almış organik herbisit bulunmamaktadır (Anonim, 2017; Kılıçarslan, 2017). Doğal dengeyi koruması, insanlar tarafından emniyetle kullanılmaları, hedef yabancı ot üzerinde etkili olması, ve doğada çabuk parçalanır olmalarından dolayı biyopestisitler organik tarımda kullanımı tercih edilmektedir (Quarles, 2013; Pacanoski, 2015). Bunun yanısıra uygulama maliyetleri ile miktarlarının yüksek olması, kısa sürelerde tekrar uygulama gerektirmesi, kontakt etkili olmaları ve yabancı otların erken gelişme dönemlerinde uygulanmaları dezavantaj olarak görülmektedir (Young, 2004; Lanini, 2010; Webber ve ark., 2012). Dünyada biyopestisit pazarının 2016 yılında 3.36 milyar \$ olduğu ve 2022 yılında 8.82 milyar \$ ulaşacağı tahmin edilmektedir (Rohan, 2016). Bu çalışmada yabancı otların mücadelesinde kullanılan, kontakt etkili organik herbisitlerin farklı uygulama konsantrasyonları BioLink \% 4 ve \% 6, Matran ${ }^{\circledR} \quad$ EC $\% 10$ ve Weed Pharm \% 100 konsantrasyonlarının adjuvan olarak Organik BioLink \% 1, Silwet* Eco Spreader \% 1 ve BreakThru ${ }^{\circledR}$ S $240 \quad \% 1$ uygulama dozları organik sebze üretim alanlarında sorun yazlık geniş yapraklı yabancı ot türlerinden Amaranthus retroflexus L., Abutilon theophrasti L. ve Solanum nigrum L.'un (Gleen, ve ark., 2009) kontrolündeki etkinliği araștırılmıştır.

\section{Materyal ve Yöntem}

Çalışma 2012 yılında Kaliforniya Üniversitesi (Amerika Birleşik Devletleri), Bitki Bilimi Bölümü seralarında yürütülmüștür. Organik Tarımda yabancı otların mücadelesinde kullanılan organik herbisitlerin farklı dozlarının $A$. retroflexus L., $A$. theophrasti L. ve $S$. nigrum L. yabancı otları üzerine olan etkinliği saptamak üzere; kontakt etkili organik herbisitler tavsiye dozlarında (Çizelge 1) sera ortamında saksılarda yetiștirilen bitkilere özel imal edilmiș kontrollü ilaçlama kabininde $3 \mathrm{~atm}$ basınçta yelpaze tipi meme (8004) dekara $35 \mathrm{gal} / \mathrm{a}$ (32.74 l/da) su miktarı ile uygulanmıştır. Ayrıca ilaç uygulamasının yapılmadığı kontrol bitkileri mukayese amaçlı yetiştirilmiştir. Uygulama bitkilerin erken gelişme dönemlerinde (3-4 yapraklı), her saksıda 1 bitki olmak üzere tesadüf blokları deneme desenine göre it üzümünde 5 tekerrürlü, imam pamuğu ve horoz ibiğinde 6 tekerrürlü olacak şekilde yapılmıştır. Uygulamalar sonrası 1., 5. ve 15. günlerde etkinlik (\%) değerleri (0-100 arasında; $0=$ etkisiz, $100=$ etkili) ölçülmüştür (Lanini, 2010; Kolören ve Lanini, 2015). Elde edilen sonuçlara Minitab 17 programı kullanılarak tek yönlü varyans (ANOVA) analizi uygulanarak ve ortalamalar arasındaki farklılıklar Duncan Çoklu Karşılaştırma Testi ile belirlenmiştir. Varyans analizi yapılmadan önce \% değerler Arcsin Transformasyonu ile düzenlenmiş olup, transforme edilmemiş veriler verilmiștir (Winer, 1971; Mennan ve ark., 2006).

Çizelge 1. Denemede kullanılan organik herbisitler ve uygulama miktarları

\begin{tabular}{|c|c|c|c|c|}
\hline Herbisitler & Aktif Madde & Adjuvanlar & Aktif Madde & Uygulama Miktarı \\
\hline BioLink & Fatty asit (\% 8) & Organik BioLink & $\begin{array}{c}\text { Yukka Ekstraktı (\%30), } \\
\text { Sarımsak Ekstraktı (\%10) }\end{array}$ & $\begin{array}{c}\text { BioLink \% } 4+\text { Organik BioLink \% } 1 \\
\text { adjuvan }\end{array}$ \\
\hline BioLink & it (\% 8) & Organik BioLink & $\begin{array}{c}\text { Yukka Ekstraktı (\%30), } \\
\text { Sarımsak Ekstraktı (\%10) }\end{array}$ & $\begin{array}{c}\text { BioLink } \% 6+\text { Organik BioLink \% } 1 \\
\text { adjuvan }\end{array}$ \\
\hline Matran $® \mathrm{EC}$ & Karanfil yağı (\% 50) & Organik BioLink & $\begin{array}{c}\text { Yukka Ekstraktı (\%30), } \\
\text { Sarımsak Ekstraktı (\%10) }\end{array}$ & $\begin{array}{c}\text { Matran }{ }^{\circledR} \mathrm{EC} \\
\% 10+\text { Organik BioLink } \% 1 \text { adjuvan }\end{array}$ \\
\hline $\begin{array}{l}\text { Weed } \\
\text { Pharm }\end{array}$ & setik asit (\% 20) & Organik BioLink & $\begin{array}{c}\text { Yukka Ekstraktı (\%30), } \\
\text { Sarımsak Ekstraktı (\%10) }\end{array}$ & $\begin{array}{c}\text { Weed Pharm } \% 100+\text { Organik BioLink } \\
\% 1 \text { adjuvan }\end{array}$ \\
\hline BioLink & Fatty asit (\% 8) & $\begin{array}{l}\text { Silwet } ® \text { Eco } \\
\text { Spreader }\end{array}$ & $\begin{array}{l}\text { Organosilikon } \\
(\% 100)\end{array}$ & $\begin{array}{c}\text { BioLink } \% 4+\text { Silwet* Eco Spreader } \% \\
1 \text { adjuvan }\end{array}$ \\
\hline BioLink & Fatty asit (\% 8) & Break-Thru® S 240 & $\begin{array}{l}\text { Organomodifiye trisiloxanes } \\
(\% 100)\end{array}$ & $\begin{array}{c}\text { BioLink \% 4 + Break-Thru® S } 240 \% \\
1\end{array}$ \\
\hline
\end{tabular}

\section{Bulgular ve Tartışma}

Denemede kullanılan bütün uygulamalar (Weed Pharm \% $100+$ BioLink \% 1 hariç) üç yabancı ot türü üzerinde değişik \% oranlarında etkili bulunmuştur. Uygulamaların yabancı ot türlerine göre etkinlikleri incelendiğinde; $A$. retroflexus bitkisinde değerlendirme günlerinde uygulanan bütün organik herbisitler (Weed Pharm \% $100+$ Biolink \% 1 hariç) \% etki olarak farklı değerlere sahip olmalarına rağmen istatistiksel olarak fark bulunmamıștır (Çizelge 2). BioLink \% 6 + Organik BioLink \% 1 adjuvan uygulamasında bütün değerlendirme günlerinde \% 100 etki saptanmıştır. A. theoprastii bitkisi 15 . gün değerlendirmesinde en 
iyi \% etki olarak BioLink \% 6 + Organik BioLink \% 1 adjuvan uygulamasında \% 84.83 olarak bulunmuştur ve istatistiksel olarak BioLink \% $4+$ Organik BioLink $\% 1$ adjuvan, Matran® EC \% 10 + Organik BioLink \% 1 adjuvan arasında fark bulunmamıștır. BioLink \% 4
+ Organik BioLink \% 1 adjuvan uygulaması, farklı adjuvan kullanılan BioLink \% $4+$ Silwet* Eco $^{*}$ Spreader \% 1 adjuvan ve BioLink \% $4+$ BreakThru® 240 S \% 1 uygulamalarına göre daha etkili bulunmuştur.

Çizelge 2. Denemede kullanılan organik herbisitlerin yabancı ot türlerine olan etkisi (\%)

\begin{tabular}{|c|c|c|c|c|c|c|c|c|c|}
\hline \multirow{3}{*}{ Uygulamalar } & \multirow{2}{*}{\multicolumn{3}{|c|}{$\begin{array}{l}\text { A. retroflexus } \\
\text { Değerlendirme Günleri }\end{array}$}} & \multirow{2}{*}{\multicolumn{3}{|c|}{$\begin{array}{l}\text { A. theoprastii } \\
\text { Değerlendirme Günleri }\end{array}$}} & \multirow{2}{*}{\multicolumn{3}{|c|}{$\begin{array}{c}\text { S. nigrum } \\
\text { Değerlendirme Günleri }\end{array}$}} \\
\hline & & & & & & & & & \\
\hline & 1. Gün & 5. Gün & 15. Gün & 1. Gün & 5. Gün & 15. Gün & 1. Gün & 5. Gün & 15. Gün \\
\hline $\begin{array}{c}\text { BioLink \% } 4+\text { Organik } \\
\text { BioLink \% } 1 \text { adjuvan }\end{array}$ & $99.66 \mathrm{a}^{*}$ & $98.33 \mathrm{a}$ & $91.66 \mathrm{a}$ & $91.66 \mathrm{a}$ & $81.50 \mathrm{a}$ & $61.50 \mathrm{a}$ & $83.80 \mathrm{~b}$ & $76.00 \mathrm{~b}$ & $82.00 \mathrm{~b}$ \\
\hline $\begin{array}{c}\text { BioLink \% } 6+\text { Organik BioLink } \\
\% 1 \text { adjuvan } \\
\end{array}$ & $100.00 \mathrm{a}$ & $100.00 \mathrm{a}$ & $100.00 \mathrm{a}$ & $97.66 \mathrm{a}$ & $94.00 \mathrm{a}$ & $84.83 \mathrm{a}$ & $96.40 \mathrm{ab}$ & $99.20 \mathrm{a}$ & $100.00 \mathrm{a}$ \\
\hline $\begin{array}{c}\text { Matran® EC \% } 10+\text { Organik } \\
\text { BioLink \% } 1 \text { adjuvan } \\
\end{array}$ & $99.66 \mathrm{a}$ & 99.66 a & $90.00 \mathrm{a}$ & $96.00 \mathrm{a}$ & $94.50 \mathrm{a}$ & $64.16 \mathrm{a}$ & $98.20 \mathrm{a}$ & $99.20 \mathrm{a}$ & $100.00 \mathrm{a}$ \\
\hline $\begin{array}{c}\text { Weed Pharm \% } 100+\text { Organik } \\
\text { BioLink \% } 1 \text { adjuvan } \\
\end{array}$ & $4.16 \mathrm{~b}$ & $2.33 \mathrm{~b}$ & $0.00 \mathrm{~b}$ & $5.00 \mathrm{~b}$ & $2.50 \mathrm{~b}$ & $0.00 \mathrm{~b}$ & $4.40 \mathrm{c}$ & $2.20 \mathrm{c}$ & $0.60 \mathrm{c}$ \\
\hline $\begin{array}{c}\text { BioLink \% } 4+\text { Silwet@ Eco } \\
\text { Spreader \% } 1 \text { adjuvan } \\
\end{array}$ & $94.83 \mathrm{a}$ & $93.33 \mathrm{a}$ & $81.66 \mathrm{a}$ & $89.50 \mathrm{a}$ & $87.83 \mathrm{a}$ & $50.00 \mathrm{ab}$ & $90.00 \mathrm{ab}$ & $94.60 \mathrm{ab}$ & $100.00 \mathrm{a}$ \\
\hline $\begin{array}{c}\text { BioLink } \% 4+\text { Break-Thru® S } \\
240 \% 1 \\
\end{array}$ & $93.66 \mathrm{a}$ & $90.50 \mathrm{a}$ & $83.33 \mathrm{a}$ & $94.50 \mathrm{a}$ & $81.00 \mathrm{a}$ & $35.00 \mathrm{ab}$ & $85.20 \mathrm{~b}$ & $84.60 \mathrm{~b}$ & $66.00 \mathrm{~b}$ \\
\hline Kontrol & $0.00 \mathrm{~b}$ & $0.00 \mathrm{~b}$ & $0.00 \mathrm{~b}$ & $0.00 \mathrm{~b}$ & $0.00 \mathrm{~b}$ & $0.00 \mathrm{~b}$ & $0.00 \mathrm{c}$ & $0.00 \mathrm{c}$ & $0.00 \mathrm{c}$ \\
\hline
\end{tabular}

* Aynı sütünda aynı harfle gösterilen uygulamalar arasında Duncan testine göre $\mathrm{P} \leq 0.05$ seviyesinde fark yoktur.

Genelde bütün uygulamalar (Weed Pharm \% $100+$ Biolink \% 1 hariç) 1. gün değerlendirmesinde \% etki değerleri yüksek iken daha sonraki değerlendirme günleri olan 5. ve 15. günlerde $\%$ etki değerleri azalmıştır. $S$. nigrum bitkisinde 15 . gün değerlendirmesinde BioLink \% $6+$ Organik BioLink $\% 1$ adjuvan, Matran® EC \% $10+$ Organik BioLink \% 1 adjuvan ve BioLink \% 4 + Silwet@ Eco Spreader \% 1 adjuvan uygulamalarında \% 100 etki saptanmıştır. 1. gün değerlendirmesinde Matran $®$ EC $\% 10+$ Organik BioLink \% 1 adjuvan uygulaması \% 98.20 ile en etkili bulunmuştur. 5. gün değerlendirmesinde ise BioLink \% $6+$ Organik BioLink \% 1 adjuvan ve Matran® EC \% 10 + Organik BioLink \% 1 adjuvan uygulamaları \% 99.20 etki oranları saptanmıştır. Weed Pharm \% 100 + Organik BioLink \% 1 uygulamasında diğer yabancı ot türlerinde olduğu gibi etkisiz bulunmuştur. S. nigrum bitkisi 1. günde $\%$ etki değerlerinin fazla olduğu BioLink \% $6+$ Organik Bioİink \% 1 adjuvan, Matran® EC \% $10+$ Organik BioLink \% 1 adjuvan ve BioLink \% $4+$ Silwet $\AA$ Eco Spreader \% 1 adjuvan uygulamalarında bitkiler tekrar gelişme gösteremeyip ilaçların \% etkisi \% 100 olarak saptanmıștır. Koloren ve Lanini (2015), sera koşullarında yaptıkları çalışmalarında organik herbisitlerden BioLink \% 6 ve \% 12, Matran® EC \% 7.5 ve \% 15 konsantrasyon uygulamalarının $S$. nigrum bitkisinin kontrolünü 15. Gün değerlendirmelerinde \% 100 oranında sağladı̆̆ bildirmişlerdir. Aynı çalışmalarında dar yapraklı yabancı ot türü olan Lolium perenne'ye karşı kullanılan organik herbisitlerden hiçbirinin etkili olmadığı bildirmişlerdir. Yabancı otların gelişme dönemleri ve dar-geniş yapraklı durumu organik herbisitlerin etkinliğinde önemli bir rol oynar. Özellikle küçük otsu geniş yapraklı yabancı otların mücadelesinde organik herbisitler daha etkindir (Smith, 2004; Boyd and Brennan, 2006; Lanini, 2011). Geniş yapraklı yabancı ot türlerinin dar yapraklı yabancı ot türlerine göre organik herbisitler tarafından iyi kontrolünün sağlandığı bildirilmektedir (James et al., 2002; Webber and Shrefler, 2007; Lanini, 2010). Birçok çalışmada asetik asit içerikli organik herbisitlerin dar yapraklı yabancl ot kontrolünde geniş yapraklı yabancı otların kontrolüne göre daha az başarı sağlandığını bildirmişlerdir (Webber and Shrefler, 2007; Abouziena et al., 2009). Aynı şekilde karanfil yağının farklı aktif madde konsantrasyonları tek-çok yıllık dar yapraklı ve geniş yapraklı yabancı otların kontrolünde etkilidir. Diğer kontakt etkili herbisitler gibi dar yapraklı yabancı otların kontrolü geniş yapraklı yabancl otların kontrolüne göre daha zordur (Webber and Shrefler, 2009; Webber et al., 2012). Hatta düşük uygulama dozları daha etkilidir. Organik herbisitlerin etkili bir kontrol sağlaması için erken kotiledon veya gerçek yaprak dönemlerinde uygulanması gerektiği belirtilmiştir (Smith, 2004; Abouziena et al., 2009). Ayrica bazı adjuvant eklemeleri ile organik herbisitlerin etkinliğini 
artabileceği saptanmıștır (Johnson, 2010). Ayrıca sıcaklık ve güneş ışığı organik herbisitlerin etkinliğini etkileyebilir. Birçok çalışmada organik herbisitlerin yaz uygulamalarının kış uygulamalarından daha etkili olduğu belirtilmiștir (Lanini, 2010).

\section{Sonuç}

Denemede kullanılan organik herbisitler (Weed Pharm \% 100+ BioLink \% 1 hariç) A. retrolexus, A. theoprastii ve $S$. nigrum bitkilerinin kontrolünde etkili bulunmuştur. Uygulamaların ekonomik maaliyet hesaplamalarının yapılarak uygulanabilirliğinin ortaya konması gerekmektedir. Ayrıca, farklı çevresel faktörlerin ilaç etkinlikleri üzerine olan etkileride belirlenmelidir.

\section{Kaynaklar}

Abouziena, H.F.H., Omar, A.A.M., Sharma S.D., Singh M., 2009. Efficacy comparison of some new naturalproduct herbicides for weed control at two growth stages. Weed Technology. 23 (3):431-437.

Anonim, 2017. Organik tarımda yabani ot mücadelesi. http://ekolojikpazarlar.org. (Erişim tarihi: 18.10.2017)

Boyd, N.S., Brennan, E.B., 2006. Burning nettle, common purslane, and rye response to a clove oil herbicide. Weed Technology. 20 (3): 646-650.

Dayan, F.E., Duke, S.O., 2010. Natural products for weed management in organic farming in the USA. Herbicides for organic growers. Outlooks on Pest Management-August 2010, 156-160.

EPA, 2008. Inert ingredients eligible for FIFRA 25(b) pesticide products. http://www.epa.gov /opprd001/ inerts/ section25b_inerts.pdf. (Erişim tarihi: 3.4.2011).

James, T.K., Rahmani, A., Trolove, M., Frith, H., 2002; Efficacy of a certified organic herbicide based on pine essence. New Zealand Plant Protection. 55:207-212.

Johnson, B., 2010. Organic herbicides becoming more effective, experts say. AgAlert (The weekly newspaper for California agriculture).

Karaaslan, V., 2015. Türkiye'de ve Doğu Karadeniz'de organik tarım. Doğu Karadeniz II. Organik Tarım
Kongresi 6-9 Ekim 2015, Pazar/Rize. Çağrılı bildiri, sayfa 1.

Koloren, O., Lanini, T., 2015. Organik herbisitler ve etkinliği", Ekoloji 2015 Sempozyumu, 6-9 Mayıs 2015, Sinop, 333 s.

Lanini, W.T., 2010. Organic herbicides - do they work? California Weed Science Society Journal. 6 (1): 1-3.

Lanini, W.T., 2011. Organic herbicides and other organic weed control approaches. Türkiye IV. Bitki Koruma Kongresi Bildirileri. 28-30 Haziran 2011, Kahramanmaraş. Çağrılı bildiri, sayfa 3.

Mennan, H., Ngouajiob, M., Isık, D., Kaya, E.,2006. Effects of alternative management systems on weed populations in hazelnut (Corylus avellana L.). Crop Protection, 25: 835-841.

Pacanoski, Z., 2015. Bioherbicides. Herbicides, physiology of action, and safety. InTech, Chapter 11. http://dx.doi.org/10.5772/61528. 253-274.

Quarles, W., 2013. New biopesticides for IPM and organic production. The IPM Practitioner Monitoring the Field of pest Management. Vol. XXXIII, 7/8 July/August 2011. 1-9.

Rohan, N., 2016. Biopesticides Market by Type (Bioinsecticides, Biofungicides, Bioherbicides, and Bionematicides), Origin (Beneficial Insects, Microbials, Plant-incorporated Protectants, and Biochemicals), Mode of Application, Formulation, \& Crop Type - Global Forecast to 2022. Marketsandmarkets.

Smith, R., 2004. Post emergence organic weed control in onions and broccoli. Crop Notes. 10-12.

Webber, C.L. III., Shrefler, J.W., 2007. Organic weed control with vinegar:application volumes and adjuvants. Proceedings of Horticultural Industry 26: 149-151.

Webber, C.L. III., Shrefler, J.W., 2009. Broadcast application of Matran for broadleaf weed control in springtransplanted onions. Weed Control Report, 162:1719.

Webber, C.L. III., Shrefler, J.W., Brandenberger, L.P., 2012. Organic weed control. InTech. 185-198.

Winer, B. J. 1971. Statistical principles and experimental desing. 2nd Edition. McGraw-Hill Book NY:397-401.

Young, S.L., 2004. Natural product herbicides for control of annual vegetation along roadsides. Weed Technology, 18. 580-587. 